\title{
PROFIL USAHA INDUSTRI BAKERY PADA PERUSAHAAN "NEW SEGAR" DI KELURAHAN PINAESAAN KECAMATAN WENANG KOTA MANADO
}

\author{
Jonathan Armando Malonda \\ Welson M. Wangke \\ Vicky R. B. Moniaga
}

\begin{abstract}
This study aims to describe the business profile of the bakery industry in the company "New Segar" in Pinaesaan Urban District Wenang Manado City. This research was conducted in January to March 2017. The data used are primary data and secondary data. This research is done by direct interview technique with company leader who holds authority and plays an important role in "New Segar" operational process. The data obtained were analyzed using descriptive analysis and presented in tabular form. The result of this research shows that the business profile of New Segar bakery industry is a cottage industry and has 8 manpower with production of 3 bread models as much as 4600 packs with production value Rp.48.300.000, for its marketing is done in Manado, Tomohon and Minahasa North. New Segar bakery business has gained profit in 1 month amounting to Rp.20.805.000.
\end{abstract}

Keywords: business profile, bakery industry, company "New Segar", Pinaesaan urban village, Wenang Sub-District, Manado City.

\begin{abstract}
ABSTRAK
Penelitian ini bertujuan untuk mendeskripsikan profil usaha industri bakery pada perusahaan "New Segar" di Kelurahan Pinaesaan Kecamatan Wenang Kota Manado. Penelitian ini dilaksanakan pada bulan Januari hingga Maret 2017. Data yang digunakan adalah data primer dan data sekunder. Penelitian ini dilakukan dengan teknik wawancara langsung dengan pimpinan perusahaan yang memegang wewenang dan berperan penting pada proses oprasional "New Segar". Data yang diperoleh dianalisis menggunakan analisis deskriptif dan disajikan dalam bentuk tabel. Hasil penelitian ini menunjukkan profil usaha industri bakery New Segar merupakan industri rumahan dan memiliki 8 orang tenaga kerja dengan produksi 3 model roti sebanyak 4600 bungkus dengan nilai produksi Rp.48.300.000, untuk pemasarannya dilakukan di Manado, Tomohon dan Minahasa Utara. Usaha bakery New Segar telah memperoleh keuntungan dalam 1 bulan sebesar Rp.20.805.000.
\end{abstract}

Kata kunci: profil usaha, industri bakery, perusahaan "New Segar”, Kelurahan Pinaesaan, Kecamatan Wenang, Kota Manado.

\section{PENDAHULUAN}

\section{Latar Belakang}

Produk bakery adalah produk makanan yang bahan utamanya adalah tepung (kebanyakan tepung terigu) dan dalam pengolahannya melibatkan proses pemanggangan. Kue sendiri ada yang dibuat melalui proses pemanggangan, ada yang tidak. Produk bakery contohnya adalah roti, biskuit, kue kering, donat, dan produk lain yang dibuat oleh tukang roti (Rahmanto, 2010).

Roti adalah makanan berbahan dasar utama tepung terigu dan air, yang difermentasikan dengan ragi, tetapi ada juga yang tidak menggunakan ragi. Namun kemajuan teknologi, manusia membuat roti diolah dengan berbagai bahan seperti garam, minyak, mentega, ataupun telur untuk menambahkan kadar protein di dalamnya 
sehingga didapat tekstur dan rasa tertentu. Roti merupakan makanan yang sudah banyak dikonsumsi sebagai alternative sumber kalori pengganti nasi pengganjal perut (Hidayat, 2009).

Seiring dengan meningkatnya perkembangan perusahaan yang berkembang di bidang industri bakery maka skala usaha yang dijalankan juga semakin beragam, mulai dari industri rumahan, kecil, sedang, sampai usaha besar. Kota Manado juga tidak terlepas dari perkembangan usaha pembuatan produk bakery. Saat ini, industri bakery merupakan salah satu industri makanan jadi di Manado yang cukup berkembang.

Kota Manado khususnya, di Kelurahan Pinaesaan, Kecamatan Wenang terdapat usaha rumahan yaitu New Segar. Usaha ini berdiri sejak tahun 1996. New Segar awalnya di kelolah secara langsung Bapak Dhani C.H. Ratu sebagai pemilik usaha, tetapi semenjak terjadinya kebaran pada pabrik New Segar pada tahun 2011, Bapak Dhani menyerahkan kepada Ibu Dien Pandenaa yang sebelumnya merupakan orang kepercayaannya dan juga sebagai karyawan pada saat itu untuk mengelolah New Segar sampai sekarang. New Segar memproduksi bermacam-macam jenis roti dengan dengan varian rasa yang berbeda yaitu jenis roti manis yang terdiri dari roti coklat, roti keju, dan roti mocca, kemudian jenis roti tawar yang terdiri dari roti segar dan roti enak dan yang terakhir jenis roti kering. Usaha ini memiliki tenaga kerja yang berjumlah 8 orang. Pemasaran New Segar di pasarkan di tiga kota, untuk Kota Manado di pasarkan di Supermarket seperti di Golden, Jumbo, Simple dan Paniki Jaya. Dan untuk Kota Tomohon di Grand Central. Dan Kota Bitung di Samudra.

\section{Rumusan Masalah}

Berdasarkan latar belakang yang telah di kemukakan, maka yang menjadi permasalahan dalam penelitian yaitu "Bagaimana profil usaha bakery "New Segar" di Kelurahan Pinaesaan, Kecamatan Wenang, Kota Manado.

\section{Tujuan Penelitian}

Mendeskripsikan profil usaha industri bakery pada perusahaan "New Segar" di
Kelurahan Pinaesaan Kecamatan Wenang Kota Manado.

\section{Manfaat Penelitian}

Manfaat dari penelitian ini untuk memberikan informasi dan masukan kepada perusahaan New Segar Manado dalam mengembangkan usaha serta dapat dijadikan sebagai bahan referensi untuk penelitianpenelitian yang terkait dengan profil usaha.

\section{METODOLOGI PENELITIAN}

\section{Waktu dan Tempat Penelitian}

Penelitian ini dilaksanakan pada industri New Segar yang berlokasi di Kecamatan Wenang, Kota Manado, dengan waktu penelitian selama tiga bulan yaitu sejak bulan Januari sampai bulan Maret 2017, mulai dari persiapan, pengumpulan data sampai penyusunan laporan penelitian.

\section{Metode Pengumpulan Data}

Pada teknik penelitian ini peneliti mengunakan metode pengumpulan data yaitu dengan pengamatan (observasi), wawancara dan dokumentasi. Karakteristik responden yang dituju adalah pihak-pihak yang memegang wewenang kebijakan yang berperan penting pada proses operasional "New Segar" Manado.

\section{Konsep dan Pengukuran Variabel}

1. Struktur organisasi industri bakery New Segar.

2. Jumlah bahan baku dan bahan penolong (Rp).

3. Biaya produksi adalah biaya tetap dan biaya variabel yang di keluarkan dalam produksi pada usaha bakery New Segar.

a. Biaya tetap adalah biaya yang besar kecilnya tidak berpengaruh terhadap jumlah produksi yang dihasilkan. Yang termasuk dalam biaya tetap yaitu, biaya penyusutan dan biaya pajak.

b. Biaya variabel yaitu biaya yang diperlukan dalam produksi bakery pada New Segar seperti, biaya bahan baku 
(Rp), biaya tenaga kerja (Rp), biaya listrik (Rp), biaya pengemasan ( $R p)$, biaya transportasi (Rp).

4. Pemasaran yaitu, tenik atau cara penyaluran produk dari produsen ke konsumen.
a. Mekanisme Pemasaran
b. Lokasi Pemasaran
c. Harga Jual
d. Jumlah Penjualan

5. Keuntungan yaitu, besarnya keuntungan yang diperoleh industri bakery New Segar (Rp).

\section{Metode Analisis Data}

Analisis data digunakan dalam penelitian ini adalah analisis data secara deskriptif, yaitu mendeskripsikan profil usaha bakery secara menyeluruh mulai dari tahap pendirian, operasional, dan menganalisa keuntungan dengan data yang dikumpulkan dari hasil wawancara dengan pimpinan perusahaan dan karyawan, dan dianalisis secara deskriptif serta disajikan dalam bentuk tabel, digunakan rumus sebagai berikut:

1. Untuk mengetahui besarnya tingkat penerimaan yang diperoleh mengunakan rumus sebagai berikut:

Dimana:

$$
\mathbf{T R}=\mathbf{P} . \mathbf{Q}
$$

$$
\begin{aligned}
\mathrm{TR} & =\text { Total Revenue }(\text { Total Penerimaan) } \\
\mathrm{P} & =\text { Price } \text { (Harga Produk) } \\
\mathrm{Q} & =\text { Quantity (Jumlah Produk) }
\end{aligned}
$$

2. Untuk mengetahui nilai penyusutan suatu barang mengunakan rumus:

$$
\mathbf{P}=\frac{\mathbf{N b}-\mathbf{N S}}{\mathbf{N}}
$$

Dimana:

$$
\begin{aligned}
& \mathrm{Nb}=\text { Nilai Beli } \\
& \mathrm{Ns}=\text { Nilai Sisa } \\
& \mathrm{N}=\text { Umur Ekonomis }
\end{aligned}
$$

3. Untuk mengetahui besarnya nilai produksi yang diguanakan dalam proses produksi bakery New Segar dapat mengunakan rumus:

Dimana:

$$
\mathbf{T C}=\mathbf{T F C}+\mathbf{T V S}
$$

$\mathrm{TC}=$ Total Biaya

TFC = Total Biaya Tetap

$\mathrm{TVC}=$ Total Biaya Variabel
4. Untuk mengetahui besar tingkat keuntungan yang diperoleh New Segar Bakery, menggunakan rumus sebagai berikut:

$$
\pi=\text { TR }- \text { TC }
$$

Dimana:

$$
\begin{aligned}
\pi & =\text { Profit }(\text { Keuntungan }) \\
\mathrm{TR} & =\text { Revenue }(\text { Total Penerimaan }) \\
\mathrm{TC} & =\text { Total Cost }(\text { Total Biaya })
\end{aligned}
$$

\section{HASIL DAN PEMBAHASAN}

\section{Derkrpisi Umum Usaha Bakery New Segar}

New Segar merupakan salah satu industri yang berasal dari industri rumahan, usaha ini berdiri sejak tahun 1996. Usaha ini berlokasi di Kelurahan Pinaesaan, Kecamatan Wenang, Kota Manado. New Segar awalnya di kelolah secara langsung bapak. Dhani CH. Ratu sebagai pemilik usaha, tetapi semenjak terjadinya kebakaran pada pabrik New Segar pada tahun 2011, Bapak. Dhani menyerahkan kepada Ibu. Dien Pandenaa yang sebelumnya merupakan orang kepercayaannya dan juga sebagai karyawan pada saat itu untuk mengelolah $\mathrm{New}$ Segar sampai sekarang.

New Segar memproduksi bermacammacam jenis roti dengan dengan varian rasa yang berbeda yaitu jenis roti manis yang terdiri dari roti coklat, roti keju, roti coklat-keju dan roti mocca, kemudian jenis roti tawar yang terdiri dari roti segar dan roti enak dan yang terakhir jenis roti kering. Usaha ini memiliki tenaga kerja yang berjumlah 8 orang. Dalam proses produksi bakery New Segar dari awal hingga akhir di butuhkan waktu tidak terlalu lama mulai dari 2-3 jam di mulai dari persiapan, pencampuran adonan (Mixing), penimbangan, pembentukan adonan, pengisian adonan, penataan adonan, pemberian bahan tambahan, pengembangan adonan (Proofing), pemanggangan, pengolesan, pendinginan dan pengemasan.

Proses produksinya dilakukan di Kelurahan Pinaesaan, Kecamatan Wenang, Kota Manado. Sedangkan untuk pemasaran New Segar Bakery di pasarkan di tiga kota, untuk Kota Manado di pasarkan di Supermarket seperti di Golden, Jumbo, Simple dan Paniki 
Jaya. Dan untuk Kota Tomohon di Grand Central. Dan Kota Bitung di Samudra.

\section{Struktur Oragnisasi New Segar}

Struktur organisasi New Segar masih sederhana, hanya terdiri dari dua bagian saja yaitu, pimpinan dan tenaga kerja. Berdasarkan hasil penelitian, struktur organisasi dalam usaha bakery New Segar dapat dilihat dalam gambar 1 .

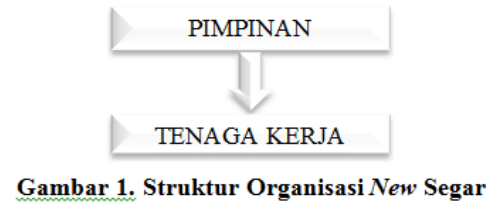

a. Nama Usaha : New Segar

b. Alamat

: Kecamatan Wenang, Kota Manado

c. Pemilik

d. Bidang Usaha

: Ibu. Dien Pandenaa

e. Mulai Usaha

: Bakery

f. Tenaga Kerja

: 2011

: 8 Orang

Industri New Segar dikelola langsung oleh pimpinan, di mana pimpinan tersebut yang mengendalikan semua kegiatan usaha. Pada bagian produksi tugasnya adalah melakukan semua proses produksi yang ada di dalam usaha tersebut, dan tugas tersebut dikerjakan oleh 6 orang. Pemilik industri membuat perencanaan dengan baik dalam usaha ini, di mana bahan baku dan bahan penolong sudah disediakan dari jauh-jauh hari sebelum digunakan, agar tidak kehabisan stok bahan baku dan bahan penolong. Pemilik juga melakukan pengontrolan pada saat proses produksi dimulai sampai akhir. Pengontrolan dilakukan, agar produk yang dihasilkan tidak mengecewakan konsumen.

\section{Penggunaan Bahan Baku dan Bahan Baku Penolong}

Bahan baku utama yang digunakan dalam pembuatan roti, yaitu tepung terigu, gula pasir, mentega, air, susu bubuk, telur, garam, ragi, dan pelembut. Bahan-bahan ini didapatkan ditokotoko terdekat, jenis tepung terigu yang digunakan adalah tepung terigu (kompas). Menurut pemilik usaha tepung terigu ini memiliki kualitas yang bagus dan tidak beda jauh dari tepung terigu yang bermerek lainnya. Pembelian tepung terigu per 1 sak Rp.180.000.
Menurut pemilik usaha, Bakery New Segar diproduksi satu hari satu kali, produksinya dilakukan pada pagi hari sampai pada siang hari. Untuk mendapatkan bahan baku lainnya seperti gula pasir, mentega, air, susu bubuk, telur, garam, ragi, dan pelembut, pemilik usaha biasanya mendapatkan ditokotoko terdekat, dan untuk air biasanya mengunakan air yang berasal dari pam. Pembelian gula pasir per 1 sak Rp.650.000, untuk mentega per 1 karton Rp.160.000, susu bubuk per $1 \mathrm{sak} / 10 \mathrm{~kg} \mathrm{Rp} .750 .000$, telur per lbak Rp.45.000, garam per 1 pak/20 bungkus Rp.20.000, dan ragi per 1 karton/20 bungkus Rp.550.000. Dalam satu kali produksi bakery biasanya New Segar memakai $20 \mathrm{~kg}$ tepung terigu, gula pasir $15 \mathrm{~kg}$, air 10 liter, susu bubuk 250 gram, 15 butir telur, garam 250 gram, ragi 200 gram. Selain bahan baku utama dibutukan juga bahan baku tambahan seperti coklat, keju, dan mocca.

\section{Penggunaan Bahan Baku Utama Selama Bulan Februari}

Bahan-bahan baku pembuatan roti New Segar Bakery adalah sebagai berikut :

- Tepung terigu dalam satu kali produksi menggunakan $20 \mathrm{~kg}=\mathrm{Rp} \cdot 144.000$. Untuk periode bulan Februari (20 hari) menggunakan $400 \mathrm{~kg}$ tepung terigu = Rp.2.880.000.

- Mentega dalam satu kali produksi menggunakan $1,5 \mathrm{~kg}$. Untuk periode bulan Februari (20 hari) menggunakan $30 \mathrm{Kg}$ mentega $=$ Rp.320.000.

- Gula pasir dalam 1 kali produksi menggunakan $20 \mathrm{~kg}=\mathrm{Rp} .260 .000$ Untuk periode bulan Februari (20 hari) menggunakan $400 \mathrm{~kg}$ tepung terigu = Rp.5.200.000.

- Air untuk satu hari menggunakan 10 liter dalam 1 kali produksi, Untuk periode bulan Februari (20 hari) menggunakan 200 liter air.

- Susu bubuk dalam satu kali produksi menggunakan 200 gram. Untuk periode bulan Februari (20 hari) menggunakan 4 kg susu bubuk = Rp.120.000.

- Telur dalam satu kali produksi menggunakan 15 butir $=$ Rp.22.500. Untuk periode bulan 
Februari (20 hari) menggunakan 300 butir telur $=$ Rp.450.000.

- Garam dalam satu kali produksi menggunakan 200 gram. Untuk periode bulan Februari (20 hari) menggunakan 1 sak $=$ Rp.20.000.

- Ragi dalam satu kali produksi menggunakan 200 gram. Untuk periode bulan Februari (20 hari) menggunakan 4 $\mathrm{kg}=\mathrm{Rp} .108 .000$.

- Pelembut dalam satu kali produksi menggunakan 20 gram. Untuk periode bulan Februari (20 hari) menggunakan $400 \mathrm{~g}=\mathrm{Rp} .200 .000$.

Tabel 1. Penggunaan Bahan Baku Utama Bakery New Segar Selama Bulan Februari 2017

\begin{tabular}{llcr}
\hline No. & Jenis Bahan & 1 Bulan & Harga $(\mathrm{Rp})$ \\
\hline 1. & Tepung Terigu & $400 \mathrm{~kg}$ & 2.880 .000 \\
2. & Mentega & $30 \mathrm{~kg}$ & 320.000 \\
3. & Gula Pasir & $400 \mathrm{~kg}$ & 5.200 .000 \\
4. & Air & $200 \mathrm{liter}$ & - \\
5. & Susu Bubuk & $4 \mathrm{~kg}$ & 120.000 \\
6. & Telur & $300 \mathrm{butir}$ & 450.000 \\
7. & Garam & $4 \mathrm{~kg}$ & 20.000 \\
8. & Ragi & $4 \mathrm{~kg}$ & 108.000 \\
9. & Pelembut & $400 \mathrm{~g}$ & 200.000 \\
\hline & Total & & 6.706 .000 \\
\hline
\end{tabular}

Sumber: Diolah dari data primer, 2017

Tabel 1. Menunjukkan bahwa penggunaan bahan baku utama bakery selama bulan Februari 2017 sebesar Rp.6.706.000.

\section{Penggunaan Bahan Baku Penolong Selama Bulan Februari}

Bahan-bahan baku penolong dalam pembuatan roti New Segar Bakery yaitu :

- Coklat dalam satu kali produksi menggunakan $25 \mathrm{~g}$. Untuk periode bulan Februari (20 hari) menggunakan $500 \mathrm{~g}=$ Rp.60.000.

- Keju dalam satu kali produksi menggunakan $25 \mathrm{~g}$. Untuk periode bulan Februari (20 hari) menggunakan $500 \mathrm{~g}=$ Rp.87.500.

- Mocca dalam satu kali produksi menggunakan $25 \mathrm{~g}$. Untuk periode bulan Februari (20 hari) menggunakan 500g = Rp.32.500
Tabel 2. Penggunaan Bahan Baku Penolong Bakery New Segar Selama Bulan Februari 2017

\begin{tabular}{llcc}
\hline No. & Jenis Bahan & 1 bulan & Harga (Rp) \\
\hline 1 & Coklat & $500 \mathrm{~g}$ & 60.000 \\
2 & Keju & $500 \mathrm{~g}$ & 87.000 \\
3 & Mocca & $500 \mathrm{~g}$ & 32.000 \\
\hline & Total & & 179.000 \\
\hline
\end{tabular}

Sumber: Diolah dari data primer, 2017

Tabel 2. Menunjukkan bahwa penggunaan bahan baku penolong bakery selama bulan Februari 2017 sebesar Rp.179.000.

\section{Proses Produksi Bakery New Segar}

Proses produksi yaitu, suatu proses terjadinya perubahan bahan mentah menjadi barang jadi yang dikerjakan oleh tenaga manusia maupun dengan tenaga kerja proses pengelolahannya, cukup mudah dilakukan dengan tersedianya bahan baku dan bahan baku tambahan yang dibutuhkan. Dibawah ini adalah proses produksi New Segar Bakery dari tahap awal hingga tahap akhir.

\section{Persiapan}

Proses persiapan pada Bakery New Segar dibagi menjadi 2, yaitu persiapan bahan dan persiapan alat. Pada persiapan bahan, bahan baku yang sebelumnya telah disimpan pada gudang dan ditimbang akan langsung dibawa menuju area produksi roti. Sedangkan pada persiapan alat, dilakukan pengolesan loyang yang akan digunakan dengan menggunakan kuas dan pengolesan meja yang akan digunakan untuk peletakan adonan roti dengan menggunakan mentega agar nantinya adonan roti yang diletakan pada meja produksi tidak menempel atau lengket.

\section{Pencampuran Adonan (Mixing)}

Proses terpenting dalam pembuatan roti manis adalah mixing atau pengadukan. Pada proses ini bahan baku diolah dan diproses menurut kerja dan fungsi masing-masing bahan. Proses ini mempunyai pengaruh besar terhadap hasil akhir roti. Pada proses mixing, kecepatan pada saat pengadukan harus sesuai, karena 
apabila pada saat pengadukan bahan-bahan tidak tercampur rata atau pengadukannya kurang mengakibatkan adonan tidak dapat mengembang begitu pula sebaliknya.

Pada New Segar, proses mixing dilakukan dengan mencampurkan tepung terigu, susu, gula, ragi, dan air dingin. Proses pencampuran ini dilakukan dengan kecepatan sedang sampai semua bahan mencampur dan kemudian ditunggu selama 15 menit sampai adonan kalis.

\section{Penimbangan}

Pada New Segar, proses penimbangan adonan roti manis dilakukan sangat bervariasi tergantung jenis roti yang ingin diproduksi. Tiap jenis roti ditimbang dengan ukuran tertentu. Untuk roti manis jenis coklat, keju, mocca ditimbang sebanyak 60 gram per jenis roti, untuk roti tawar sebanyak 500 gram, dan untuk roti kering ditimbang sebanyak 500 gram.

\section{Pembentukan Adonan}

Proses pembagian adonan di New Segar merupakan tahapan yang penting karena proses pembagian adonan ini berpengaruh besar pada keseragaman produk akhir. adonan dibagi-bagi terlebih dahulu sebelum akhirnya dibulatkan kembali dan di proofing lagi. Proses pembagian adonan di New Segar masih dilakukan dengan manual atau menggunakan insting. Kemudian adonan dibentuk sesuai dengan jenis roti yang ada.

\section{Pengisian adonan}

Proses pengisian adonan yang dilakukan pada Bakery New Segar juga bervariasi, tergantung jenis roti yang ingin diproduksi. Roti manis yang diproduksi oleh New Segar sendiri memiliki tiga variasi rasa. Variasi rasa jenis produk roti yang diproduksi oleh New Segar antara lain roti manis seperti, coklat, keju, coklat-keju, mocca, roti tawar, enak dan segar, dan roti kering. Pada New Segar pengisian bahan ke dalam adonan roti manis dilakukan secara manual oleh karyawan New Segar, hal ini memiliki tujuan untuk mempersingkat waktu proses produksi roti manis, tetapi pada sisi negatifnya menyebabkan kurang seragam isian yang diberikan pada adonan roti manis karena karyawan New Segar masih menggunakan sistem perkiraan.

\section{Penataan Adonan}

Di New Segar, proses penataan adonan ini menjadi penting karena berpengaruh pada pengambilannya nanti setelah matang dari proses pengovenan. Peletakan harus dilakukan secara seimbang dengan diberi jarak yang sama antar adonan roti yang akan di oven. Bentuk loyang yang digunakan bervariasi, tergantung jenis roti yang ingin dibuat. Sebelum adonan roti diletakan pada talang, talang akan diolesi terlebih dahulu dengan menggunakan pelumas.

Pengolesan ini bertujuan supaya roti yang terbentuk setelah proses pengovenan tidak menempel atau lengket pada talang. Apabila saat dilakukan pemanggangan, talang tidak diolesi dengan pelumas terlebih dahulu maka akan menemui kesulitan dalam pengambilan roti setelah proses pengovenan, sehingga nantinya ketika produk ini sudah siap dikemas terdapat banyak cacat pada alas produk karena pengambilan yang kurang halus dan terlalu lengket pada talang. Jadi, pihak New Segar menggunakan pelumas untuk olesan pada talang.

\section{Pemberian Bahan Tambahan}

Setelah adonan roti manis diletakan ke dalam loyang maka, para karyawan akan melakukan pemberian bahan tambahan. Bahan tambahan yang digunakan untuk setiap jenis roti manis berbeda-beda tergantung pada jenis roti. Pada New Segar hanya roti kering yang menggunakan bahan tambahan gulan pasir dan mentega.

\section{Pengembangan Adonan}

Tahap selanjutnya adalah tahap pengembangan adonan. Pada tahap ini adonan yang telah dicetak kemudian diletakan pada talang roti dan di diamkan selama 1-2 jam atau hingga adonan mengembang sempurna.

\section{Pemanggangan}

Proses pemanggangan adalah salah satu proses yang paling penting pada New Segar. Proses pemanggangan ini bertujuan untuk 
memaksimalkan pelepasan gas supaya menghasilkan pengembangan yang jauh lebih cepat. Pada proses pemanggangan ini mengunakan oven dengan suhu $180^{\mathrm{C}}$ selama 20 menit.

\section{Pengolesan}

Produk yang sudah matang dan yang telah dikeluarkan dari oven kemudian akan diolesi dengan menggunakan susu cair. Pengolesan dengan susu bertujuan supaya warna roti menjadi lebih mengkilap sehingga menjadi lebih menarik.

\section{Pendinginan}

Roti yang telah diolesi dengan mengunakan susu kemudian akan langsung didinginkan dengan cara diangin-anginkan pada rak-rak yang telah disediakan sebelum dikemas dan didiamkan selama beberapa saat. Hal ini dilakukan untuk mencegah timbulnya titik-titik air ketika dilakukan pengemasan yang nantinya akan memicu tumbuhnya jamur pada roti tersebut dan daya simpannya relatif pendek.

\section{Pengemasan}

Proses pengemasan pada Bakery New Segar dilakukan secara manual dengan palstik oleh karyawan New Segar. Kemasan yang digunakan oleh New Segar berupa kemasan plastik mika dan plastik tebal. Kemasan plastik harus bersifat tidak beracun, sehingga tidak menyebabkan perubahan produk, misalnya warna, citarasa, tekstur, dan perubahan lainnya.

\section{Produksi}

Produksi merupakan hasil kegiatan dari suatu perusahaan untuk memproses dan menciptakan bahan baku menjadi barang jadi. Pengolahan roti merupakan salah satu proses produksi, dimana bahan baku atau bahan mentah diubah menjadi bahan jadi yang bias dikomsumsi oleh konsumen. New Segar memproduksi roti dengan jenis dan rasa yang berbeda.

Dapat dilihat pada Tabel 3. Jumlah atau volume produksi produksi selama periode bulan Februari 2017, jumlah yang dihasilkan untuk roti manis yaitu sebanyak 1.200 bungkus Rp.13.600.000 untuk roti tawar yaitu sebanyak
2.400 bungkus Rp.27.200.000 dan untuk roti kering yaitu sebanyak 1.000 Bungkus Rp.7.500.000.

Tabel 3. Jumlah Produksi dan Total Penjualan Bakery New Segar Selama Bulan Februari 2017

\begin{tabular}{ccccccc}
\hline $\begin{array}{l}\text { Periode } \\
\text { (Minggu) }\end{array}$ & \multicolumn{3}{c}{$\begin{array}{c}\text { Jumlah Produksi } \\
\text { (/ bungkus) }\end{array}$} & \multicolumn{3}{c}{ Nilai Produksi (Rp) } \\
\hline & Roti & Roti & Roti & Roti & Roti & Roti \\
Manis & Tawar & Kering & Manis & Tawar & Kering \\
\hline I & 300 & 600 & 250 & 3.400 .000 & 6.800 .000 & 1.875 .000 \\
II & 300 & 600 & 250 & 3.400 .000 & 6.800 .000 & 1.875 .000 \\
III & 300 & 600 & 250 & 3.400 .000 & 6.800 .000 & 1.875 .000 \\
IV & 300 & 600 & 250 & 3.400 .000 & 6.800 .000 & 1.875 .000 \\
\hline Jumlah & 1.200 & 2.400 & 1.000 & 13.600 .000 & 27.200 .000 & 7.500 .000 \\
\hline Sumber: Diolah dari data primer, 2017
\end{tabular}

\section{Biaya Produksi}

Biaya produksi yaitu, biaya yang dikeluarkan dalam suatu kegiatan industri untuk mengubah bahan baku seperti tepung terigu menjadi roti. Biaya produksi juga harus mengetahui biya tetap dan biaya variabel, maka biaya produksi dapat dihitung berdasarkan penjumlahan antara biaya tetap dan biaya variabel. Total Biaya Produksi New Segar adalah sebesar Rp.27.403.000

\section{Biaya Tetap}

Tabel 4. Total Biaya Tetap New Segar Selama Bulan Februari 2017

\begin{tabular}{llr}
\hline No. & Uraian Biaya & Jumlah $(\mathrm{Rp})$ \\
\hline 1 & Biaya Penyusuatan & 618.000 \\
2 & Biaya Pajak & 1.200 .000 \\
\hline & Total & 1.818 .000 \\
\hline
\end{tabular}

Sumber : Diolah dari data primer, 2017

Tabel 4. Menunjukan bahwa biaya tetap sebesar Rp.1.818.000.

\section{Biaya Pajak}

Biaya pajak industri bakery New Segar yang dikeluarkan per bulan yaitu, Rp.100.000 dan pajak per tahunnya sebesar Rp.1.200.000.

\section{Biaya Penyusutan}

Proses produksi roti menggunakan beberapa jenis alat-alat yang merupakan biaya tetap industri New Segar dalam memproduksi roti, alat-alat tersebut akan mengalami penyusutan seiring dengan lamanya pemaikain. Pada tabel 5 dapat dilihat jenis dan nilai biaya tetap serta penyusutannya. 
Tabel 5. Jenis, Nilai dan Modal Tetap Serta Penyusutan New

\begin{tabular}{|c|c|c|c|c|c|c|}
\hline $\begin{array}{l}\mathrm{N} \\
\mathrm{O}\end{array}$ & Jenis & $\begin{array}{l}\text { Jumlah } \\
\text { (Unit) }\end{array}$ & $\begin{array}{c}\text { Haraga } \\
\text { Beli (Rp) }\end{array}$ & $\begin{array}{c}\text { Umur } \\
\text { Ekonomis } \\
\text { (Bulan) }\end{array}$ & $\begin{array}{l}\text { Nilai Sisa } \\
\text { (Rp) }\end{array}$ & $\begin{array}{c}\text { Nilai } \\
\text { Penyusutan }\end{array}$ \\
\hline 1 & $\begin{array}{l}\text { Mesin Roll } \\
\text { Harga }\end{array}$ & 2 & 70.000 & 24 & 7.000 & 2.625 \\
\hline 2 & $\begin{array}{l}\text { Mesin } \\
\text { Selotip }\end{array}$ & 3 & 20.000 & 12 & 2.000 & 1.500 \\
\hline 3 & $\begin{array}{l}\text { Keranjang } \\
\text { Roti }\end{array}$ & 15 & 90.000 & 48 & 9.000 & $1.687,5$ \\
\hline 4 & $\begin{array}{l}\text { Timbangan } \\
\text { Biasa }\end{array}$ & 10 & 150.000 & 36 & 15.000 & 3.700 \\
\hline 5 & $\begin{array}{l}\text { Timbangan } \\
\text { Digital }\end{array}$ & 1 & 125.000 & 24 & 12.500 & $4.687,5$ \\
\hline 6 & Toples Isian & 10 & 25.000 & 12 & 2.500 & 1.875 \\
\hline 7 & Talang Roti & 200 & 50.000 & 24 & 5.000 & 1.875 \\
\hline 8 & Mixer & 1 & 40.000 .000 & 60 & 4.000 .000 & 600.000 \\
\hline & Jumlah & & 40.530 .000 & & & 618.000 \\
\hline
\end{tabular}

Sumber : Diolah dari data primer, 2017

Tabel 5. Menunjukkan bahwa biaya penyusutan sebesar Rp.618.000.

\section{Biaya Variabel}

Biaya variabel adalah biaya-biaya yang dikeluarkan setiap kali proses produksi dilakukan. Biaya variabel yang dikeluarkan oleh industri bakery New Segar selama bulan Februari 2017 dapat dilihat pada Tabel 6.

Tabel 6. Total Biaya Variabel New Segar Bakery Selama Bulan Februari 2017

\begin{tabular}{|c|c|c|}
\hline No. & Uraian Biaya & Jumlah (Rp) \\
\hline 1. & Biaya Bahan Baku & 6.706 .000 \\
\hline 2. & Biaya Bahan Penolong & 179.000 \\
\hline 3. & Biaya Tenaga Kerja & 12.000 .000 \\
\hline 4. & Biaya Pengemasan & 1.600 .000 \\
\hline 5. & Biaya Listrik & 600.000 \\
\hline 6. & Biaya Transportasi & 4.500 .000 \\
\hline Total & & 25.585 .000 \\
\hline
\end{tabular}

Sumber : Diolah dari data primer, 2017

Tabel 6. Menunjukkan bahwa biaya variabel sebesar Rp.25.585.000

\section{Biaya Bahan Baku}

Bahan baku memiliki peran penting dalam memproduksi suatau barang atau produk karena tanpa bahan baku suatu industri tidak dapat menghasilkan sesuatu. Oleh sebab itu, kualitas bahan baku menjadi pertimbangan utama dalam pembelian bahan baku. Bahan baku yang digunakan dalam satu kali produksi yaitu $20 \mathrm{~kg}$ tepung terigu dengan harga per $1 \mathrm{~kg}$ Rp.7.200. dan dalam 1 bulan menggunakan 400 kg Rp.2.880.000, Untuk air diperoleh dari pam. Penggunaan gula pasir dalam satu kali produksi selama bulan Februari sebanyak $400 \mathrm{~kg}$ dengan harga Rp.2.880.000. Untuk susu bubuk sebanyak 4 kg dengan harga Rp.120.000. Untuk air menggunakan 200 liter. Mentega sebanyak $30 \mathrm{~kg}$ dengan harga Rp.320.000 Untuk telur sebanyak 300 butir Rp.450.000. dan garam 1 sak sebesar Rp.20.000, ragi 4kg Rp.108.000, pelembut 400 g sebesar Rp.20.000.

\section{Biaya Bahan Baku Penolong}

Bahan penolong adalah bahan-bahan yang digunakan dalam kegiatan produksi yaitu, coklat, keju, mocca. Penggunaan Bahan penolong dalam satu kali produksi selama bulan Februari, coklat 500g sebesar Rp.60.000, keju 500g Rp.87.000, mocca 500g Rp.32.000.

\section{Biaya Tenaga Kerja}

Biaya tenaga kerja adalah biaya yang dikeluarkan untuk membayar para pekerja yang terlibat didalam suatu indutri atau perusahaan. Dalam industri bakery New Segar terdapat 8 orang tenaga kerja. Untuk satu orang diberi upah sebesar Rp.1.500.000 per bulan. Industri ini mengeluarkan upah tenaga kerja pada bulan Februari 2017 sebesar Rp.12.000.000, untuk 8 orang tenaga kerja.

\section{Biaya Pengemasan}

Biaya pengemasan adalah biaya yang dikeluarkan dalam proses pengemasan produk berbagai jenis roti. Selama periode bulan Februari 2017 sebesar Rp.1.600.000.

\section{Biaya Listrik}

Biaya listrik adalah biaya yang dikeluarkan oleh industri bakery New Segar dalam produksi berbagai jenis roti. Pemakaian peralatan listrik yang dipakai selama periode bulan Februari 2017 sebesar Rp.600.000

\section{Biaya Transportasi}

Biaya transportasi adalah biaya yang dikeluarkan pada saat memasarkan produk ke pedagang pegencer selama periode bulan Februari 2017 Rp.4.500.000. Dalam satu hari menggunakan 25 liter bensin Rp.8.000.

\section{Pemasaran}

Pemasaran adalah sebagai suatu proses social dan managerial yang membuat individu dan kelompok memperoleh apa yang mereka 
butuhkan dan inginkan lewat penciptaan dan pertukaran timbal balik produk dan nilai dengan orang lain (Kotler, 2006).

Pemasaran adalah kegiatan penyaluran bakery New Segar dari produsen sampai ke konsumen. Penyaluran bakery New Segar yaitu ke pedagang pengecer terlebih dahulu sebelum ke konsumen.

Untuk penyaluran dilakukan langsung oleh pemilik industri dan untuk alat transportasi seperti motor dan mobil kanvas yang digunakan untuk menbantu kelancaran pemasaran bakery New Segar.

Bakery yang dihasilkan dalam satu kali produksi setiap harinya. Untuk hari senin sampai jumat Roti Manis Coklat, Keju, Mocca industri ini menghasilkan sebanyak 300 bungkus, untuk 60 bungkus dipasarkan di Jumbo, Simple, Paniki Jaya, Samudra dan Grand Central.

Untuk Roti Tawar Enak dan Segar industri ini menghasilkan sebanyak 600 bungkus dan dipasarkan di Golden, Jumbo, Simple, Paniki Jaya, Samudra dan Grand Central, dan untuk Roti Kering industri ini menghasilakan sebanyak 250 bungkus dan dipasarkan di Golden, Jumbo, Simple, Paniki Jaya, Samudra.

\section{Mekanisme Pemasaran}

Mekanisme pemasaran produk yaitu, yang pertama saluran pemasaran satu tingkat yaitu usaha "New Segar" menjual produknya pada supermarket (Golden, Simple, Paniki Jaya, Jumbo, Grand Central Tomohon, Samudra Bitung).

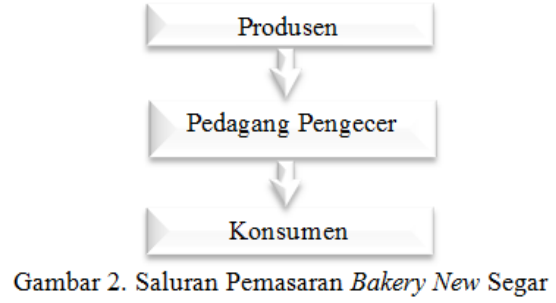

Dapat dilihat pada gambar 2. Menunjukan saluran pemasaran Bakery New Segar, dimana industri Bakery New Segar akan memasarkan produknya kepedangang pengecer terlebih dahulu dan kemudian dijual ke konsumen akhir.
Tabel 7. Pemasaran Produk Roti New Segar Bakery

\begin{tabular}{|c|c|c|c|c|c|}
\hline \multirow{2}{*}{$\begin{array}{c}\text { Tempat } \\
\text { Pemasaran }\end{array}$} & \multicolumn{3}{|c|}{ Pesanan/Bungkus (Bulan) } & \multirow{2}{*}{$\begin{array}{l}\text { Mekanisme } \\
\text { Pemasaran }\end{array}$} & \multirow{2}{*}{$\begin{array}{c}\text { Perjanjian } \\
\text { Pembayaran } \\
\text { Hasil Penjualan }\end{array}$} \\
\hline & $\begin{array}{c}\text { Roti } \\
\text { Manis } \\
\end{array}$ & $\begin{array}{c}\text { Roti } \\
\text { Kering } \\
\end{array}$ & $\begin{array}{c}\text { Roti } \\
\text { Tawar } \\
\end{array}$ & & \\
\hline Golden & - & 120 & 50 & $\begin{array}{l}\text { Diantar oleh } \\
\text { Industry }\end{array}$ & $\begin{array}{c}\text { System } \\
\text { Konsinyasi }\end{array}$ \\
\hline Jumbo & 60 & 120 & 50 & $\begin{array}{l}\text { Diantar oleh } \\
\text { Industry }\end{array}$ & $\begin{array}{c}\text { System } \\
\text { Konsinyasi }\end{array}$ \\
\hline Simple & 60 & 120 & 50 & $\begin{array}{l}\text { Diantar oleh } \\
\text { Industry }\end{array}$ & $\begin{array}{l}\text { System } \\
\text { Konsinyasi }\end{array}$ \\
\hline $\begin{array}{l}\text { Paniki Jaya } \\
\text { (P.J) }\end{array}$ & 60 & 120 & 50 & $\begin{array}{l}\text { Diantar oleh } \\
\text { Industry }\end{array}$ & $\begin{array}{c}\text { System } \\
\text { Konsinyasi }\end{array}$ \\
\hline Samudra & 60 & 120 & 50 & $\begin{array}{l}\text { Diantar oleh } \\
\text { Industry }\end{array}$ & $\begin{array}{c}\text { System } \\
\text { Konsinyasi }\end{array}$ \\
\hline $\begin{array}{l}\text { Grand } \\
\text { Central }\end{array}$ & 60 & 120 & - & $\begin{array}{l}\text { Diantar oleh } \\
\text { Industry }\end{array}$ & $\begin{array}{c}\text { System } \\
\text { Konsinyasi }\end{array}$ \\
\hline
\end{tabular}

Sumber : Diolah dari data primer, 2017

\section{Lokasi Pemasaran}

Lokasi pemasaran roti oleh industri Bakery New Segar dapat dilihat pada Tabel 7 dimana roti ini dipasarkan ditiga tiga kota. Untuk Kota Manado dipasarkan seperti Golden, Simple, dan Paniki Jaya, dan untuk Kota Tomohon di Grand Central dan untuk Kota Bitung di Samudra.

\section{Harga Jual}

Bakery New Segar memproduksi 3 jenis roti dengan varian rasa yang berbeda, untuk harga jual bakery New Segar yaitu:

1. Roti Manis Coklat

Harga untuk roti manis coklat yaitu Rp.12.000/bungkus. Untuk penjualan roti manis coklat selama satu minggu sebanyak 100 bungkus, yaitu Rp.1.200.000.

2. Roti Manis Keju

Harga untuk roti manis keju yaitu Rp.12.000/bungkus. Untuk penjualan roti manis keju selama satu minggu sebanyak 100 bungkus, yaitu Rp.1.200.000.

3. Roti Manis Mocca

Harga untuk roti mocca yaitu Rp.10.000/bungkus. Untuk penjualan roti manis mocca selama satu minggu sebanyak 100 bungkus, yaitu Rp.1.000.000.

4. Roti Tawar Segar

Harga untuk roti tawar segar yaitu Rp.12.000/bungkus. Untuk penjualan roti tawar segar selama satu minggu sebanyak 400 bungkus, yaitu Rp.4.800.000.

5. Roti Tawar Enak

Harga untuk roti tawar enak yaitu Rp.10.000/bungkus. Untuk penjualan roti tawar enak selama satu minggu sebanyak 200 bungkus, yaitu Rp.2.000.000. 
6. Roti Kering

Harga untuk roti kering yaitu Rp.7.500/bungkus. Untuk penjualan roti kering selama satu minggu sebanyak 250 bungkus, yaitu Rp.1.875.000

\section{Jumlah Penjualan}

Untuk penjualan dalam satu minggu Bakery yang dihasilkan dalam satu kali produksi setiap harinya. Untuk hari senin sampai jumat Roti Manis Coklat, Keju, Mocca industri ini menghasilkan sebanyak 300 bungkus. Untuk Roti Tawar Enak dan Segar industri ini menghasilkan sebanyak 600 bungkus dan untuk Roti Kering industri ini menghasilakan sebanyak 250 bungkus.

\section{Penerimaan dan Keuntungan Bakery New Segar}

\section{Penerimaan}

Penerimaan merupakan hasil yang diperoleh dari jumlah produksi dikali dengan harga jual. Jumlah penerimaan industri Bakery New Segar Selama bulan Februari 2017.

Tabel 8. Penerimaan New Segar Bakery

\begin{tabular}{llccc}
\hline No. & Jenis Roti & $\begin{array}{c}\text { Harga } \\
\text { Jual (P) }\end{array}$ & $\begin{array}{c}\text { Jumlah } \\
\text { Produksi } \\
(\mathrm{Q})\end{array}$ & $\begin{array}{c}\text { Penerimaan } \\
(\mathrm{Rp})\end{array}$ \\
\hline 1. & $\begin{array}{l}\text { Roti Manis } \\
\text { Coklat }\end{array}$ & 12.000 & 400 & 4.800 .000 \\
2. & $\begin{array}{l}\text { Roti Manis } \\
\text { Keju }\end{array}$ & 12.000 & 400 & 4.800 .000 \\
3. & $\begin{array}{l}\text { Roti Manis } \\
\text { Mocca }\end{array}$ & 10.000 & 400 & 4.000 .000 \\
4. & $\begin{array}{l}\text { Roti Tawar } \\
\text { Segar }\end{array}$ & 12.000 & 1.600 & 19.200 .000 \\
5. & $\begin{array}{l}\text { Roti Tawar } \\
\text { Enak }\end{array}$ & 10.000 & 800 & 8.000 .000 \\
6. & Roti Kering & 1.000 & 7.500 & 7.500 .000 \\
\hline Total & \multicolumn{3}{c}{48.300 .000} \\
\hline Sumber : Diolah dari Data Primer
\end{tabular}

Sumber : Diolah dari Data Primer, 2017

Tabel 8, menunjukkan bahwa penerimaan yang diperoleh industri bakery New Segar adalah sebesar Rp.48.300.000 selama bula Februari 2017.

\section{Keuntungan}

Keuntungan industri bakery New Segar selama bulan Februari 2017, untuk 20 kali produksi sebesar Rp.20.805.000.

$$
\pi=\text { TR-TC }
$$

Dimana:

$\pi=$ Profit (Keuntungan)

$$
\begin{aligned}
& \mathrm{TR}=\text { Revenue }(\text { Total Penerimaan }) \\
& \mathrm{TC}=\text { Total Cost } \text { (Total Biaya) } \\
& \mathrm{TR}-\mathrm{TC}=48.300 .000-27.403 .000 \\
& =20.897 .000
\end{aligned}
$$

\section{KESIMPULAN DAN SARAN}

\section{Kesimpulan}

New Segar Merupakan industri yang berkategori industri rumahan. Usaha ini berlokasi di Kelurahan Pinaesaan, Kecamatan Wenang, Kota Manado, dan memiliki 8 orang tenaga kerja dengan jam kerja yang bervariasi 4-8 jam (HOK). Produksi roti selama bulan Februari 2017 untuk 3 model roti adalah 4.600 bungus, dengan nilai produksi Rp.48.300.000. Untuk pemsarannya dilakukan di Manado, Tomohon dan Minahasa Utara. Berdasarkan hasil analisa selama bulan Februari 2017, usaha bakery New Segar telah memperoleh keuntungan sebesar Rp.20.897.000.

\section{Saran}

Berdasrkan penelitian yang telah dilakukan, maka saran yang dapat diberikan kepada New Segar yaitu : Perlu diperluas lagi pemasaran roti New Segar di seluruh Sulawesih Utara agar masyarakat lebih mengetahui produk ini. Perlu tambahan jenis roti agar semakin banyak variasi bakery yang diproduksi dengan varian rasa yang berbeda-beda.

\section{DAFTAR PUSTAKA}

Hidayat H. A. 2009. Analisis Faktor-faktor yang Mempengaruhi Penerapan Manajemen Mutu Terpadu pada Galih Bakery, Tanggerang, Banten. Skripsi Program Studi Agribisnis, Fakultas Sains dan Teknologi, Universitas Islam Negeri Syarif Hidayatullah Jakarta.

Kotler P. 2006. Manejemen Pemasaran. Edisi 12, Pengalih Bahasa Benyamin Molan 2007. PT. Indeks. PT. Macanan Jaya Cemerlang.

Rahmanto A. R. 2010. Analisis Strategi Pengembangan Usaha "Elsari Brownies dan Bakery" Kota Bogor Jawa Barat. Skripsi Fakultas Ekonomi dan Manajemen Institut Pertanian Bogor. Bogor 2010. 